Supplementary material

Atmospheric Chemistry and Physics paper ACP-2010-958

\title{
The impact of temperature changes on summer time ozone and its precursors in the Eastern Mediterranean
}

\author{
U. Im ${ }^{1}$, K. Markakis ${ }^{2}$, A. Poupkou ${ }^{2}$, D. Melas ${ }^{2}$, A. Unal ${ }^{4}$, E. Gerasopoulos ${ }^{3}$, N. \\ Daskalakis $^{1}$, T. Kindap ${ }^{3}$, M. Kanakidou ${ }^{1 *}$
}

[1] Environmental Chemical Processes Laboratory (ECPL), Department of Chemistry, University of Crete, Heraklion, Greece

[2] Aristotle University of Thessaloniki, Department of Physics, Laboratory of Atmospheric Physics, Thessaloniki, Greece

[3] Institute for Environmental Research and Sustainable Development, National Observatory of Athens, Athens, Greece

[4] Istanbul Technical University, Eurasia Institute of Earth Sciences, Istanbul, Turkey

* Correspondence to: M. Kanakidou (mariak@chemistry.uoc.gr) 

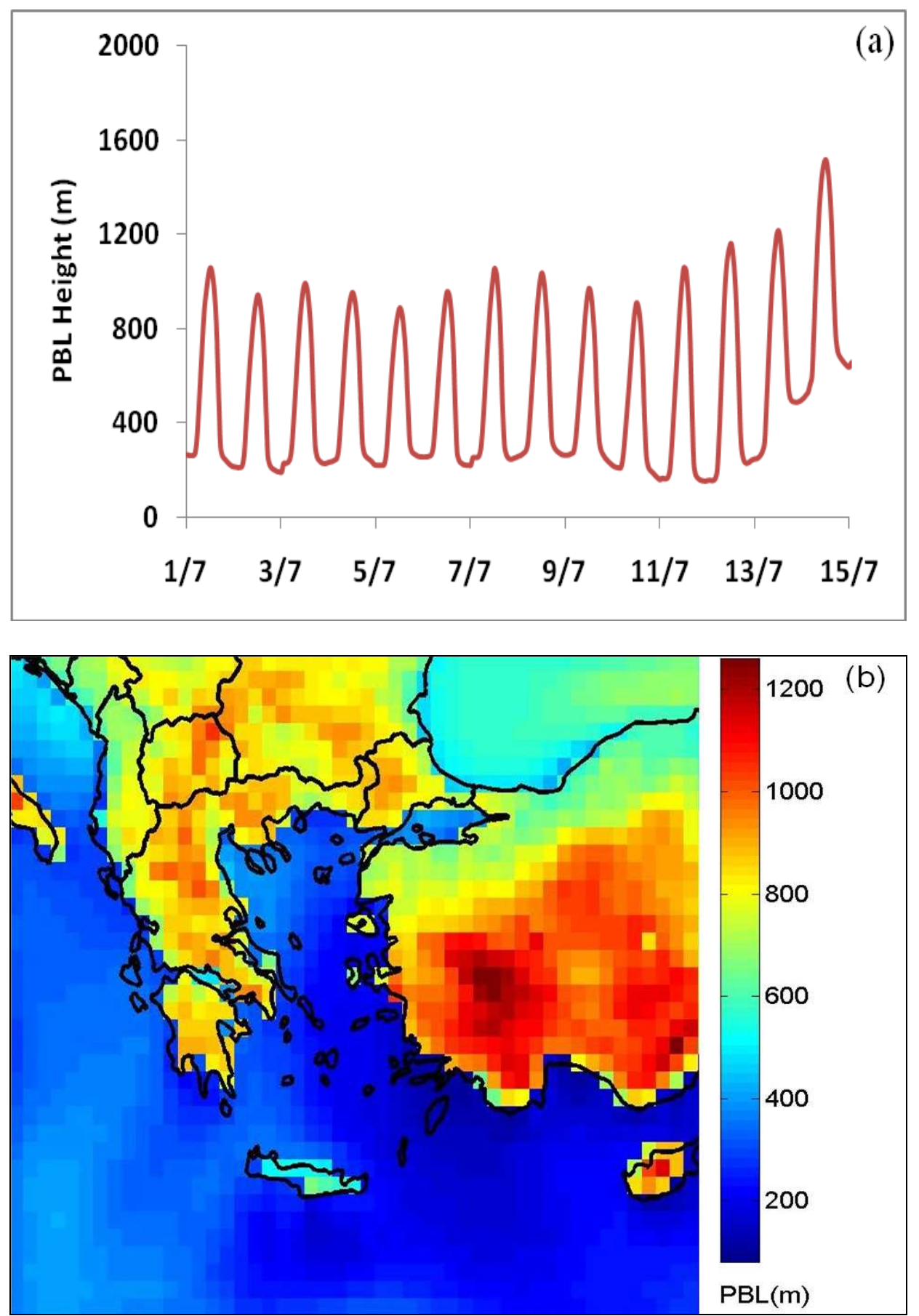

Fig. S1. a) Temporal variability of domain-averaged hourly mean PBL heights and b) spatial variability of mean PBL heights averaged over the 15-day simulation period. 


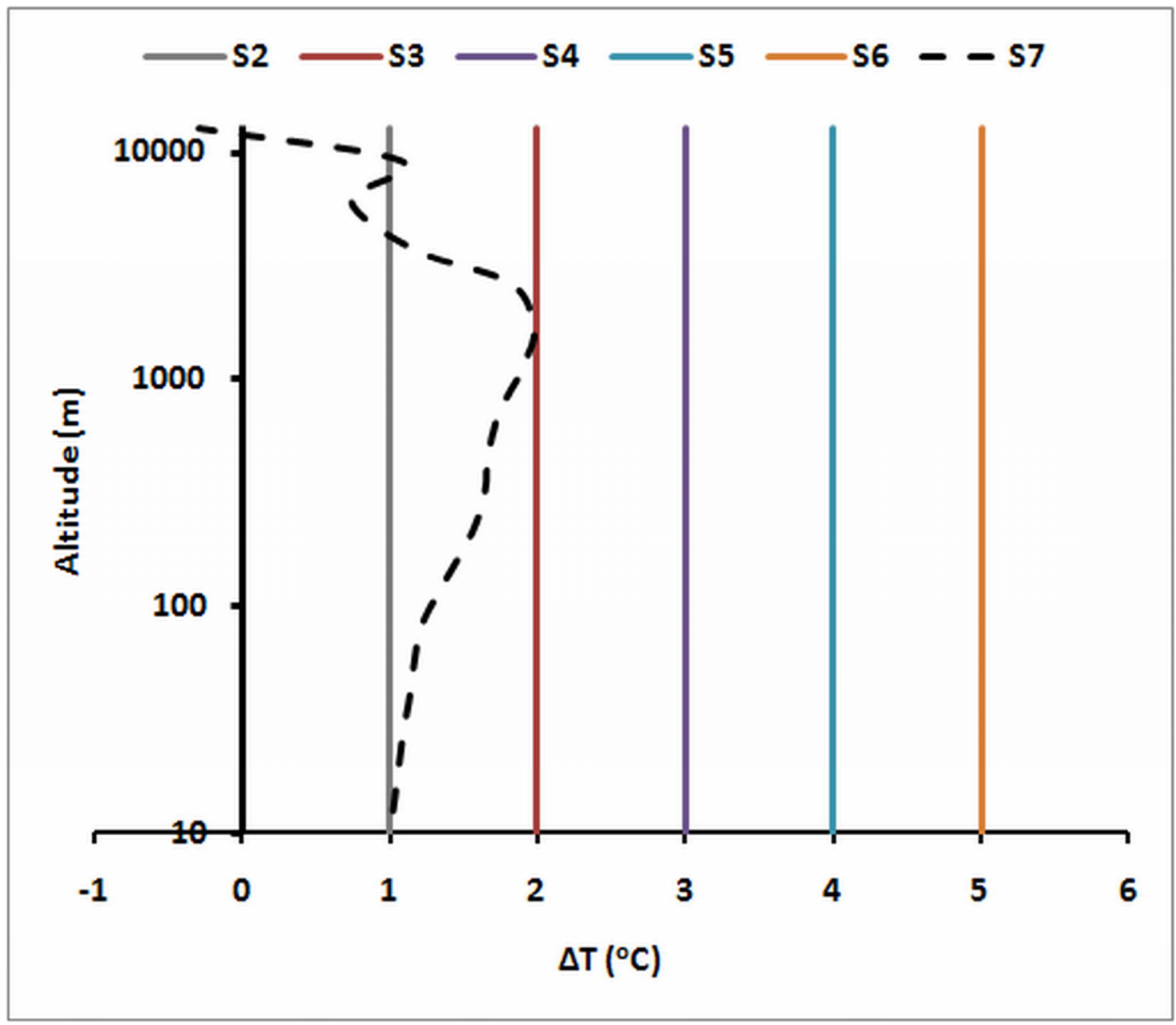

Fig. S2. The difference of mean vertical temperatures between scenarios and base case simulations. 


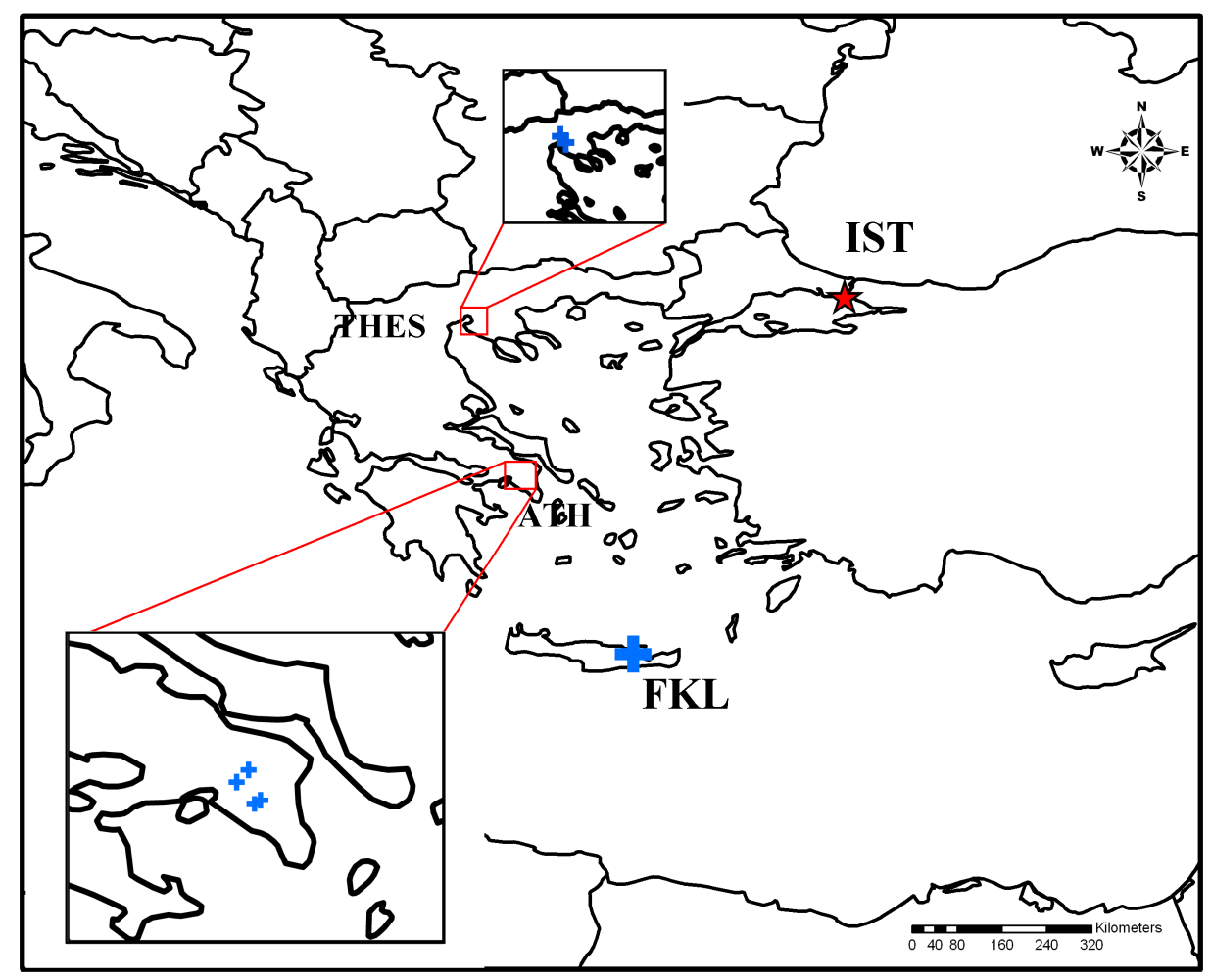

Fig. S3. Locations of the air quality monitoring stations (The geographical information for the stations are provided in Table 1). 
Table S1. Comparison of deposition velocity of ozone, soil temperature, soil moisture, wind speed at FKL and the domain-averaged cloud fractions for the different scenarios.

\begin{tabular}{lccccccc}
\hline & S0 & S1 & S2 & S3 & S4 & S5 & S6 \\
\hline $\begin{array}{l}\text { Deposition } \\
\text { velocity }\left(\mathrm{m} \mathrm{s}^{-1}\right)\end{array}$ & 0.00255 & 0.00255 & 0.00255 & 0.00255 & 0.00255 & 0.00255 & 0.00260 \\
\hline $\begin{array}{l}\text { Soil temperature } \\
(\mathrm{K})\end{array}$ & 290.844 & 290.844 & 290.844 & 290.844 & 290.844 & 290.844 & 293.698 \\
\hline $\begin{array}{l}\text { Soil moisture } \\
\left(\mathrm{m}^{3} \mathrm{~m}^{-3}\right)\end{array}$ & 0.2180 & 0.2180 & 0.2180 & 0.2180 & 0.2180 & 0.2180 & 0.2175 \\
\hline $\begin{array}{l}\text { Wind speed } \\
\left(\mathrm{m} \mathrm{s}^{-1}\right)\end{array}$ & 3.04 & 3.04 & 3.04 & 3.04 & 3.04 & 3.04 & 2.93 \\
\hline $\begin{array}{l}\text { Precip. cloud } \\
\text { cover (\%) }\end{array}$ & 0.003 & 0.003 & 0.003 & 0.003 & 0.003 & 0.003 & 0.005 \\
\hline $\begin{array}{l}\text { Non-precip. } \\
\text { cloud clover (\%) }\end{array}$ & 0.011 & 0.002 & $2.68 \mathrm{E}-4$ & $3.67 \mathrm{E}-5$ & $2.45 \mathrm{E}-6$ & $4.81 \mathrm{E}-8$ & 0.012 \\
\hline
\end{tabular}

\section{Model performance metrics}

The statistical parameters applied in this study to evaluate model performance are: correlation coefficient (r: Eq. 1), Mean Normalized Bias (MNB: Eq. 2) and Index of Agreement (IOA: Eq. 3).

$$
\begin{aligned}
& r=\left[\frac{\frac{1}{N} \sum_{i=1}^{N}\left(O_{i}-\bar{O}\right)\left(P_{i}-\bar{P}\right)}{\sigma_{O} \sigma_{P}}\right] \\
& M N B=\frac{1}{N} \sum_{i=1}^{N}\left(\frac{P_{i}-O_{i}}{O_{i}}\right) \\
& I O A=1-\frac{\sum_{i=1}^{N}\left(P_{i}-O_{i}\right)^{2}}{\sum_{i=1}^{N}\left(\left|P_{i}-\bar{O}\right|+\left|O_{i}-\bar{O}\right|\right)^{2}}
\end{aligned}
$$


where $O_{i}$ and $P_{i}$ stand for observations and predictions at each time step, $\bar{O}$ and $\bar{P}$ stand for the daily mean of observations and predictions, and $\sigma$ stands for standard deviation. 